\title{
Reconstructing the Changing Urban Landscape beyond Spatio-Temporal Dimensions: Post-colonial 'Allahabad' in Neelum Saran Gour's Invisible Ink
}

\author{
Chhandita Das ${ }^{1} \&$ Priyanka Tripathi ${ }^{2}$ \\ ${ }^{1}$ Institute Fellow (PhD), Department of Humanities and Social Sciences, Indian Institute of \\ Technology Patna.daschhandita1993@gmail.com \\ ${ }^{2}$ Associate Professor of English, Department of Humanities and Social Sciences, Indian Institute of \\ Technology Patna. priyankatripathi@iitp.ac.in. ORCID: oooo-ooo2-9522-3391.
}

\begin{abstract}
:
One of the pressing concerns of our times is the rapid change of urban landscape resulting in environmental degradation. However, there are other concerns too that leads this paper to deliberate on how individual and collective experiences and identities get reshaped extensively with the change of urban landscape across temporality. Within this framework, this paper analyses Neelum Saran Gour's novel Invisible Ink (2015) which projects Indian city 'Allahabad', now referred as 'Prayagraj' in two different time scales with a gap of forty-four years mostly through the subjective experiences of two women characters, Rekha and Amina. In the conventional discipline of Geography, landscape is often assumed to be a visual entity (Cresswell, 2015) but appropriating Leila Scannell and Robert Gifford's "Defining Place Attachment: A Tripartite Organizing Framework" (2010), landscape (both built and natural) unfolds its meaning more through human interaction constructing cultural values leading to spatial distinctiveness which is always in flux. Thus, urbanization is not just a transformation of physical topography of the 'city' but 'includes the changing façade of socio-cultural environments which unquestionably impacts on the existing values of both private and public space reshaping the experiences of its people. Therefore, this article will also examine the ways in which literature documents urban spaces.
\end{abstract}

Keywords: 'Landscape', 'Urbanization', 'Experience', 'Identity', 'Public space’ etc.

"What eternity is to time, the Aleph is to space. In eternity, all time-past, present, and future- coexists simultaneously. In the Aleph, the sum total of the spatial universe is to be found in a tiny shining sphere barely over an inch across.”

- "The Aleph”, by Jorge Luis Borges

Borges in the lines above invariably exemplifies the depth of a particular place in shaping authorial imagination and also imbibes the concerns of renowned urban geographer Edward Soja who came up with his most notable contribution on urban space Thirdspace: Journeys to Los Angeles and Other Real-and-Imagined Places (1996) which is often considered as one of the key compositions behind 'spatial turn'. It is this iconoclastic turn in the spatial study which reflects upon the importance of space on the similar notions of 'time' or for that matter history in shaping human experiences. Remarkably enough, space and time are not distinct to each other, rather complementary as they both are in process of incessant change and not beyond the range of literary representation of landscapes particularly in the context of approaching urbanism within a

(C) AesthetixMS 2020. This Open Access article is published under a Creative Commons Attribution Non-Commercial 4.0 International License (http://creativecommons.org/licenses/by-nc/4.0/), which permits non-commercial re-use, distribution, and reproduction in any medium, provided the original work is properly cited. For citation use the DOI. For commercial re-use, please contact editor@rupkatha.com 
city. However, within such spatio-temporal dimension, urbanism not only results in the transformation of physical topography of the 'city' but includes the changing façade of sociocultural environments which unquestionably impacts the individual and collective experiences and identities accordingly. Within this framework, this paper intends to analyze Neelum Saran Gour's novel Invisible Ink (2015) which projects Indian city 'Allahabad', now renamed as 'Prayagraj' in two different time scales with a gap of forty-four years, to be precise, mostly through the experiences of two women characters from the novel, Rekha and Amina. Extending the argument, the paper will also reflect that it is not just a record of Allahabad city in different time-scale but if minutely looked into, Gour's spatial representation somehow echoes Malcolm Miles' vision that "literature, in any case, does not merely record times and places; it asks questions and raises issues, takes sides and introduces otherwise unheard voices" (2019, p. ix).

In the conventional discipline of Geography, landscape (both built and natural) is often assumed as a visual entity (Cresswell, 2015) but the recent development in the spatial studies widens the scope to consider landscape beyond visual aesthetics since landscape is much more than "what our eyes see ... . [but] always points to something else, to something beyond itself..." (Paz, 1973, p.15) Therefore, it is a complex but dynamic concept which undergoes continuous modification with the passage of time, either by nature or by cultural interferences. To draw upon such line of landscape change particularly by human interference multidisciplinary approach needs to be accounted as the nuances of space has been explored in diverse disciplines like Geography, Environmental psychology, Existential philosophy etc. reflecting the modes of shaping human life contingent upon alterations taking place with space. If the space is a city or for that matter urban area, then the process of urbanization is the most pressing human inference within, that across temporality and transforms the physical topography of the landscape along with individuals' experiences and also "leads to fragmentation of social coherence and social identity" (Kaymaz, 2013, p.747) affecting collective identities. Such fragmented reality of human cultural interference through urbanization within a landscape can nicely be bridged up taking cues from authorial imagination that literature often scopes for with its spatial representation of cities i.e. textstädte (Mahler, 1999) within and beyond its people's active participation.

Such representation of urban landscapes, in literary texts appears fascinating to the Indian English authors for last few decades and Salman Rushdie's representation of 'Bombay' and Anita Desai's 'Calcutta' are some iconic instances of this phenomena. Considerably enough such citybased writings as well as research interests on urban space particularly in India, are strictly found centered around metropolitans like Delhi, Mumbai, Kolkata etc. often sideling the comparatively smaller urban areas with ethnographic heritage. Drawing upon this gap, 'The Hindu Literary Award' winner Indian English author Neelum Saran Gour's spatial representation of Allahabad within and beyond her fictional narratives is a significant one to decode. Allahabad, one of the antique cities of Northern India, is situated on the confluence of three holy rivers Ganga, Yamuna and Saraswati. This city is recently renamed as Prayagraj which means 'the king of devotion', which is possibly an attempt to revive the rich ancient Hindu cultural significance within its naming previously ignored when the city was named as 'Illahabad' by Mughal emperor Akbar from its ancient name Prayag, as per the information mentioned on government websites. Since Gour has refers it as Allahabad throughout her narrative, the article will follow the same.

Gour's novel Invisible Ink visualizes the aftermath of urbanization in the city of 'Allahabad' comparing and contrasting the subjective experiences of two women characters, Rekha and Amina in two different time scales. In the novel, the adolescence of these two girls towards 196os is largely shaped by their experiences of residential Allahabad 'Bulbul Kothi' and other spaces like 
streets, natural landscapes of the city but following the non-linear time-shifting of forty-four years and parallel portrayals are drawn that reflect upon both, the topographical transformation of 'Bulbul Kothi' to 'Bulbul Apartment' and the changing mode of spatial experiences of people in individual as well as on a collective scale. The change of urban topography and human life apparently may appear distinct issues but both are interrelated and consist of mutual coherence. The link between landscape and people is rooted largely on human experience and this has been brilliantly framed by Leila Scannell and Robert Gifford in their tripartite framework (2010) concocting between 'place', 'person' and 'process' which conveniently makes way for 'place attachment'. Here 'place' refers to both natural and built environments and 'person' stands for the individual as well as cultural groups and 'process' involves affection, cognition and behavior extensively. Within this framework, Gour's narrative unfolds in-depth meanings as her characters' cognition and behaviors are explicitly resonant with changing urban landscapes of Allahabad.

The novel Invisible Ink begins with a kaleidoscopic view of contemporary Allahabad through the vision of Rekha and Amina, Rekha being the first-person narrator. It is Amina's return to her native after her long stay in the UK and therefore, the new urban module of their residential 'Bulbul Kothi' surprises her unquestionably when Rekha addresses it as 'Bulbul Apartment' to the rickshaw puller: "Amina half-turns in surprise...instead of the large tree-shaded field, which our Bulbul Kothi overlooked, there is a tall, square apartment block, the rear wings of which abut our old haveli ${ }^{2}$. Our lane has shrunk, its sunlight cut off" (Gour, 5-6). Such physical change of landscape can easily be sighted but beyond it lies individual cognitions about that space which allow to compare them the previous one with present or for that matter 'environmental past' (Proshansky, 1983, p.59) to judge present. One of the most prominent cognitive tools for such comparison is memory through which often the meaning of landscapes are generated (Hay, 1998) as a place is not just a physical land, rather its meaning depends largely on human interactions. The same is not beyond Gour's fictional representation where both Rekha and Amina's memory takes them to visualize previous topography of their once shared domestic space of 'Bulbul Kothi' terrace:

The terrace was our territory with its freckled walls yellow and black-pitted like scaly, sunburnt skin. We spent hours dangling our long, skinny arms over the peeling plaster of the low brickwork wall, idly contemplating the street, or sat perched on a bench, trailing our toes in the golden wash of thickening winter sun. (Gour, p.6)

Therefore, the terrace transcends from a physical landscape to the realm of these women's experience or friendship and consequently becomes an inseparable part of their spatial cognition in the form of memory which definitely adds special meaning to it.

The importance of such human experiences within a landscape to generate meaning has also been outlined in L. C. Manzo's article "For Better or Worse: Exploring Multiple Dimensions of Place Meaning" (2005) as for her "it is not simply the places themselves that are significant, but rather what can be called 'experience-in-place' that creates meaning" (p.74). It is not that human experiences only add meaning to landscapes, rather human experiences also undergone changes due to landscapes particularly within and beyond the urbanization process which often makes the landscapes overcrowded as well as artificial. The same also becomes visible when Rekha after a long in her matured age takes her mother to Human temple on the banks of river Ganga and can easily notice the physical changes of her city across temporality: "Everything has changed, the broad Fort Road, noisy with traffic, and the fairgounds of the Magh Mela ${ }^{3}$ looking shrunken and unmysterious" (Gour, p.16). Beyond the physical changes, Rekha's memory also allows her to capture changes of experiences as previously there was freshness of air in the temple yard, 
chirping of birds but at present, there are multiple artificialities like Army barricades, metal detector, close-circuit camera, security checking etc. and in narrator's cognition "all done in a tentative atmosphere of misapprehension very disorienting to our accustomed span and pitch of devotional engagement. We almost missed meeting our old Lord Hanuman in this fast-forward hurtle" (Gour, p.18). This 'fast-forward hurtle' is definitely an offshoot of urbanity in Allahabad resulting in overcrowded spaces as well as insecurity which changes accordingly Rekha's, her mother's and definitely for so other pilgrims' experiences of Hanuman Temple mostly by reducing the time of their actual prayer.

Public domains are basically those domains which allow easy access to all (Low and Smith, 2006) and traditionally temples are open to everyone but with the approaching urbanization, it also undergoes change with time-restricted access to the temple premise for the devotees. Since place is a substructure of a person's self-identity (Proshansky, 1978), it has an equal stake within collective identity as people come to identify themselves within that particular place and considerably enough, such collective spatial identification is indivisible from people's life. Therefore, when there are immense changes within the urban landscape resulting in sheer changes of collective experiences that consequently makes room for fragmented or split identity, even on a collective scale. Issues with Rekha's mother are similar as after her experiences of the Allahabad Hanuman temple that gives outlet to her baffled questions: "Is this the same temple?" ... Are we the same people?" (Gour, p.18) manifests of how the disparity between past and present experiences of the same landscape due to urbanism causes a crisis in self. Unquestionably, here topographical changes transcend from the physicality to the realm of human consciousness resulting split in collective identification. In fact, such spatial changes are so vehement that they transform familiar into unfamiliar and known to unknown in human cognition.

Beyond cognition, another important attribute of Scannell and Gifford's tripartite frame between 'person' 'place' and 'process', is 'affection' as there is always a grain of emotional bonding between these two. This affection can be a person's love for a landscape within and beyond aesthetics and cultural variations which is termed as 'topophilia' (Tuan, 1974). Mostly it is an emotion that one feels for his/her 'home' which simply doesn't refer to a building of dwelling, rather as contested phenomena it can refer to cities and nations as well where one can locate his/her real 'self. Likely for Gour's characters namely Rekha and even for Amina after her long stay in Birmingham, it is still Allahabad which gives ease like 'home' and such affection or love from Amina's part is visible in her own utterance as for her 'home' is that place where "you locate your dreams in... In some dreams, it's this Bulbul Kothi. It's that terrace, the courtyard below" (Gour, p.86). Importantly enough it is only this dream which impels her desire to own a flat in the same locality of Allahabad but implicitly in Amina's dream, it is always the previous topography of the landscape with trees, sunlight, open courtyard and chirping of Bulbul ${ }^{4}$ birds that exist, not the vision of present 'Bulbul Apartment' with security guard at the gate. Therefore, when she is denied a flat in the same area, her long-cherished love for 'Bulbul Kothi' shapes into anguish for urban 'Bulbul Apartment' and in her emotional outburst, she says: "I wish we'd just stayed on here. We'd never have sold half of Bulbul Kothi” (Gour, p.140).

The reason behind such sheer anguish of Amina is the authority's denial for a flat to her and it is extensively because of the placid changes of social or for that matter communal tension in that particular landscape. Apparently, landscape and social relations may look distant but for Ittelson. et al there is hardly any physical environment that is not also a social environment, and vice-versa (1974). It is because when people share a common space, there invariably comes a keenness among them as part of their spatial experiences together which often generates 'sense of 
community' (Nasar \& Julian,1995). Such 'community of place' shares social ties deeply rooted in various places including neighborhoods, streets, shops, natural landscapes or any other spaces engaging social interaction. In fact, it is the same kind of community sense based on the place that people of Allahabad shared in the 1960 s which is evident from the 'Bulbul Kothi' neighbors interaction reflected in Gour's fictional representation in Invisible Ink. The neighbors from diverse religious backgrounds like Hindu, Muslim etc. not only live in the same locality but they have shared belief in each other's festivals and mutually partake in festivals of which Gour mentions many a time in Invisible Ink. Rekha being a Hindu went to Gazi Mian's shrine to offer chadar (coverlet) as part of festival. In the house Rekha's mother's religious fasting and their rented guest Mehru's Ramzan ${ }^{6}$ celebration received equal value as "Ramzan and the month of Sravan were coinciding" (Gour, p.108), and it was the same city where Mehru's father recited Urdu version of Gayetri mantra ${ }^{7}$ for his daughter without hesitation.

All such intersected spaces of shared beliefs of people generate a distinct community sense within their city Allahabad and reflection can be visualized in the utterance of Rekha: "our city had stories of Muslims escorting Hindu baraats $^{8}$ through troubled pockets and Hindu families hiding Muslim neighbours in their homes for days while the trouble lasted" (Gour, p. 208). Here Gour's representation of communal harmony in the early 1960 is not romantically decorated but speak of minor difference of opinions that is congenital in the social system. However, such minor differences within social relations turn into a massive gap both with the flow of time as well as the spatial reconstruction of the city. It is not only the political mishaps that generate fragmentation between Allahabadi Hindu and Muslim's shared collective identity but it is equally an offshoot of the urban apartment culture of the city that separates these two religious groups with different colonies for each one of them. In fact, this is the sole reason behind the authority's denial to sell a flat to Amina in contemporary 'Bulbul Apartment' as Rekha's says, "to them you (Amina) are a Muslim. If you want a house to buy or rent, you'll have to look in a Muslim area” (Gour, p.140). Therefore, the innate experiences of Amina and Rekha's adolescent friendship shared in 'Bulbul Kothi' terrace, becomes only a part of utopic fascination in the contemporary urban apartment culture of Allahabad.

However, beyond built landscapes like streets, buildings, etc. cities also comprise natural landscapes that also undergo changes across temporality in topographical scale with human advancement, resulting in discursive shifting of human experiences within it. Such natural landscapes often extend signification in terms of intangible values (like festivals, rituals, beliefs, practices etc.) inextricably linked with the spatiality itself and thereby, generating distinct 'cultural landscapes' which has been nicely elaborated by Carl O. Sauer: "the cultural landscape is fashioned from a natural landscape by a cultural group. Culture is the agent, the natural area is the medium, and the cultural landscape is the result" (1925, p.19). Here spatiality attaches distinct cultural values to a particular natural landscape which also changes with approaching urbanity that even touches upon the intangible values of that space. In the context of Allahabad city, the most remarkable natural landscape is the Sangam or confluence of three holy rivers Ganga, Yamuna and Saraswati which beyond the topographic aesthetic visibility, is considered in Hindu tradition as the holiest for its water which is believed to carry nectar to cleanse all early sins. To commemorate its holiness every year Magh mela has been organized in the month of January in this particular natural landscape turning it to a 'cultural landscape'. Therefore, Janet Stephenson appropriately asserts that 'culture and identity are not merely about social relationships, but also spatial' (2008, p.84) and the same is for Magh mela organized in Sangam. Considerably enough Neelum Saran Gour reflects upon such spatial culture in Invisible Ink while representing 
Allahabad and also accounts for the changes of Sangam's natural landscape both in tangible and intangible scale with distinct swings of human experiences within.

Such natural landscapes are essentially part of 'public space' as it provides free and open access to all (Festas, 2012, p.3) and the same is for Allahabad Sangam. Down to memory lane Rekha has narrated how she, her step-mother, Amina, Danish and cousins of Amina went for a day out in Allahabad Sangam where "Ganga with the morning sun striking it a blinding fish-scale silver. The jade-green Yamuna and the long spine of tangling waters that unfurl like a shining bale and pouring into that far horizon. And our third river. The Saraswati." (Gour, p.62). It is not that they just got mesmerized by the topographical mystery of the landscape but also experience the very nuances of the landscape within its cultural ambiance of Magh mela organized "acres upon acres of bamboo pavilions, its dense grid of sandy pathways" (Gour, p.66). In the fairground, the overcrowded gathering of holy men, pilgrims, horoscope charters, ash smeared Naga sadhus ${ }^{9}$ and others, fascinated them with a mystifying appeal. But across temporality with human advancement the flow and greenery of the rivers get affected as per the narrator's perception, "our two rivers, the Ganga reduced to muddy, infected slime, the Yamuna a wide, swollen sewer" (Gour, p.191). Beyond such environmental degradation, the landscape of Sangam's cultural ground also gets shrunk due to the urbanization process of concretizing the dusty paths; even technology erodes the ascetic charm of the sadhus in the mela as they now rely on laptops for prophecy. It somehow changes the experiences of people too and that's why Rekha in her adult age refers that the mela no more generates mysterious appeal to her as there are only artificialities within it. Therefore, access to natural public space by all remains the same with urbanism but unquestionably it changes people's experiences within.

One can conclude that changes due to urbanity may not always shape human experiences with a negative connotation as evident from Gour's representation of urban Allahabad, particularly in the context of gender access to public spaces rather, it is a construction that cannot be judged for it comprises grey areas of human existence involving their ideology, attitude, temperament and belief system from diverse standpoint. Socially women are "imposed role in the private as opposed to the public sphere, in the home rather than in the street, inside rather than in the world outside" (Reus \& Usandizaga, 2008, p.19) and the same was visible in 1960's Allahabad society where Leelavati as a single parent of Rekha accessed only home space. Remarkably enough, Gour's unbiased narration here exhibits how domestic space can also be utilized for sustenance beyond a space of gender violence, where a mother met existential need of money both by giving rent a 'Bulbul Kothi' room and also starting sewing at home where customers themselves came to her, however, for sewing materials she had to depend on a male neighbor. As the time swings, gender access of public spaces by women becomes pertinent in urban Allahabad where women also go outside home for their sustenance and access newly built streets, markets, stores as per their need. The same is reflective in Rekha's later life when she as a seamstress like her mother ekes out living but "taking orders from stores" (Gour, p.185) herself. Therefore, without any grain of doubt gender experiences have also undergone changes in urban Allahabad.

Tracking the changing nuances of human life both, in the subjective and collective milieu of urban Allahabad contrasting with past, it becomes explicit that people's experiences get reshaped extensively with the change of urban landscape across temporality. It is extensive because landscapes are never neutral in human life and so are human beings for cities and that's why Arvind Krishna Mehrotra once mentioned that "Allahabad's is a terribly human story" (2017, p.7). It signifies the indivisible interrelation between people and this city constructing meaning 
for one another through interaction and quite notably such spatial meanings are always in flux. Thus, urbanization not just enhances the transformation of physical topography of the 'city' but includes the changing façade of socio-cultural environments both in natural and built landscapes, which unquestionably impacts on the existing values and accesses of public space and implicitly on domestic space, reshaping the experiences of its people. Significantly it is the beauty of literature that provides wide scope to underpin such often sidelined spatial shaping of human experiences across temporality beyond urban topographical changes and reflections taken from Neelum Saran Gour's Invisible Ink, evidently approves this.

\section{Notes:}

'Spatial turn' is basically an intellectual move that emphasizes upon the role of space in social sciences. It proves influential for research in diverse disciplines like History, Cartography, Literature etc.

'2'Haveli' refers to a town house or mansion in Indian subcontinent.

${ }^{3}$ 'Magh mela' is the yearly version of Kumbh mela constituting series of Hindu festivals. This 'mela' or fair is mostly organized in Allahabad during month of January-February beside the confluence of three holy rivers Ganga, Yamuna and Saraswati.

${ }^{4} \mathrm{Bulbul}$ is a small singing bird to be found in tropical Asia to Indonesia.

${ }^{5 ‘ R a m z a n ' ~ i s ~ a ~ m o n t h ~ o f ~ f a s t i n g ~ a n d ~ p r a y e r ~ w i t h i n ~ M u s l i m ~ c o m m u n i t y ~}$

${ }^{6}$ In Hindu tradition 'Sravan' or 'Shravana' is a holy month and many festivals like Naga-Panchami, Govatsa, Shravani Purnima, Vara Lakshmi Vrata etc., are celebrated during this month.

${ }^{7}$ Gayetri mantra is a most revered sacred utterance in Hindu tradition and it has been widely recited in Vedic and post-Vedic ages.

${ }^{8}$ Baraat is a Hindi word which refers marriage procession.

${ }^{9}$ Naga sadhus are Hindu ascetics who remain naked except for garlands and rosary beads. They all assemble in Kumbh mela or Magh mela for holy bathing in sangam of Ganga, Yamuna and Saraswati rivers.

\section{References:}

Borges, J. (1971). The Aleph and Other Stories: 1933-1969. New York: Bantam Books.

Cresswell, T. (2015). Place: An Introduction. United Kingdom: Wiley Blackwell.

Festas, M. J. (2012). Public Space. Futuropa: For a New Vision of Landscape and Territory, (3). Retrieved from https://rm.coe.int/ogoooo168093e66c

Gour, N. S. (2015). Invisible Ink. Noida: Harper Collins Publishers India.

Hay, R. (1998). Sense of Place in Developmental Context. Journal of Environmental Psychology, 18(1), 5-29. doi: 10.1006/jevp.1997.0060

Ittelson, W. H. et al. (1974). An Introduction to Environmental Psychology. New York: Holt, Rinehart and Winston.

Kaymaz, I. (2013). Urban Landscapes and Identity. In Özyavuz, M. (Ed.), Advances in Landscape Architecture, (pp. 739-76o). Croatia: InTech.

Low, S., \& Smith, N. (2006). The Politics of Public Space. New York: Routledge. 
Mahler, A. (1999). Stadt-Bilder: Allegorie - Mimesis - Imagination. Heidelberg: C. Winter.

Mehrotra, A. K. (2007) qtd. in Editors Preface. Indian Literature, LI (1), 5-7.

Manzo, L. C. (2005). For Better or Worse: Exploring Multiple Dimensions of Place Meaning. Journal of Environmental Psychology. 25(1), 67-86. doi: 10.1016/j.jenvp.2005.01.002

Miles, M. (2019). Cities and Literature. New York: Routledge.

Nasar, J. L., \& Julian, D. A. (1995). The Psychological Sense of Community in the Neighborhood. Journal of American Planning Association, 61(2), 178-184. doi: 10.108o/01944369508975631

Paz, O. (1973). Alternating Current. New York: The Viking Press.

Proshansky, H. M. (1978). The City and Self-Identity. Environment and Behavior. 10(2), 147-169. doi: 10.1177/0013916578102002

Proshansky, H. M. et al. (1983). Place-Identity: Physical World Socialization of the Self. Journal of Environmental Psychology. 3(1), 57-83. doi: 10.1016/So272-4944(83)80021-8

Reus, T. G., \& Usandizaga, A. (2008). Inside Out: Women Negotiating, Subverting, Appropriating Public and Private Space. New York: Rodopi.

Sauer, C. O. (1925). The Morphology of Landscape. University of California Publications in Geography. 2, 1953 .

Scannell, L., \& Gifford, R. (2010). Defining Place Attachment: A Tripartite Organizing Framework. Journal of Environmental Psychology. 30(1), 1-10. doi: 10.1016/j.jenvp.2009.09.006

Soja, E. (1996). Thirdspace: Journeys to Los Angeles and Other Real-and-Imagined Places. Cambridge: Blackwell.

Stephenson, J. (2008). The Cultural Values Model: An Integrated Approach to Values in Landscapes. Landscape and Urban Planning. 84(2), 127-139. Doi: 10.1016/j.landurbplan.2007.07.003

Tuan, Y. (1974). Topophilia: A Study of Environmental Perception, Attitudes and Values. New Jersey: Prentice Hall. 